\title{
Determinants of increases in stillbirth rates from 2000 to 2010
}

\author{
K.S. Joseph MD PhD, Brooke Kinniburgh MPH, Jennifer A. Hutcheon PhD, Azar Mehrabadi MSc, \\ Melanie Basso RN MSN, Cheryl Davies RN MEd, Lily Lee RN MPH
}

\begin{abstract}
Background: After decades of decline, stillbirth rates have increased in several industrialized countries in recent years. We examined data from the province of British Columbia, Canada, in an attempt to explain this unexpected phenomenon.

Methods: We carried out a retrospective population-based cohort study of all births in British Columbia from 2000 to 2010. Outcomes of interest included overall stillbirth rates, birth weightand gestational age-specific stillbirth rates, rates of spontaneous stillbirths (excluding pregnancy terminations that satisfied the definition of stillbirth [fetal death with a birth weight $\geq 500 \mathrm{~g}$ or gestational age at delivery $\geq 20 \mathrm{wk}$, hereafter referred to as "pregnancy terminations") and rates of congenital anomalies among live-born infants. We used logistic regression to adjust for changes in maternal age, parity, weight before pregnancy and multiple births.
\end{abstract}

Results: Overall, stillbirth rates increased by $31 \%$ (95\% confidence interval $[\mathrm{Cl}] 13 \%$ to $50 \%$ ), from
8.08 per 1000 total births in 2000 to 10.55 per 1000 in 2010. The rate of stillbirths with a birth weight of less than $500 \mathrm{~g}$ increased significantly $\left(p_{\text {trend }}=0.03\right)$, whereas the rate of stillbirths with a birth weight of $1000 \mathrm{~g}$ or more decreased significantly $\left(p_{\text {trend }}=0.009\right.$ ). The rate of spontaneous stillbirths decreased nonsignificantly by $16 \%$, from 5.7 per 1000 total births in 2000 to 4.8 per 1000 in 2010. There was a significant decline of $30 \%(95 \% \mathrm{Cl} 6 \%$ to $47 \%)$ in the rate of spontaneous stillbirth with a birth weight of $1000 \mathrm{~g}$ or more between 2000 and 2010; adjustment for maternal factors did not appreciably change this temporal effect. The prevalence of congenital anomalies among live-born infants decreased significantly, from 5.21 per 100 live births during the first 3 years (2000-02) to 4.77 per 100 during the final 3 years (2008-10).

Interpretation: Increases in pregnancy terminations were responsible for the increases observed in stillbirth rates and were associated with declines in the prevalence of congenital anomalies among live-born infants.
Competing interests: None declared.

This article has been peer reviewed.

Correspondence to: K.S. Joseph, kjoseph @cw.bc.ca

CMAJ 2013. DOI:10.1503 /cmaj.121372
$\mathrm{A}$ fter decades of steady decline, stillbirth rates have increased or plateaued in several industrialized countries in recent years. In Canada, the stillbirth rate increased from 6.0 per 1000 total births in 2000 to 7.1 per 1000 in 2009. ${ }^{1,2}$ Similarly, stillbirth rates in Australia increased from 7.0 per 1000 total births in 2000 to 7.8 per 1000 in $2009,{ }^{3.4}$ and rates in New Zealand increased from 7.8 per 1000 total births in 2007 to 8.5 per 1000 in $2009 .{ }^{5-7}$ The decline in stillbirth rates has levelled off in recent years in the United Kingdom (5.4 per 1000 total births in 2000 and 5.2 per 1000 in $2009^{8}$ ) and stopped in the United States (6.2 per 1000 total births in 2003 and $2005^{\circ}$ ).

The prevention of stillbirth through early delivery of the compromised fetus is considered the cornerstone of modern obstetrics. ${ }^{10}$ The recent trends in stillbirth rates are therefore disquieting given developments in fetal surveillance techniques, increased monitoring of high-risk pregnancies and simultaneous increases in obstetric intervention. One potential explanation is the recent increase in risk factors for stillbirths in industrialized countries, namely increases in higher maternal age, weight before pregnancy and multiple births. ${ }^{11-13}$ Another explanation is the widespread availability and increasing uptake of technologies such as prenatal diagnosis and pregnancy termination for severe congenital anomalies (which can result in a fetal death that satisfies the current definition of stillbirth).

Although rising or static rates of stillbirth in high-income countries are of national and international concern, the underlying causes for the trends are best examined at a subnational level, because detailed information on maternal, fetal and infant characteristics and on obstetric care services is available only in high-quality perinatal databases that capture information on a regional basis. We therefore carried out a study to explain the recent temporal increase in stillbirth rates using data from the province of British Columbia, Canada. 


\section{Methods}

\section{Data source}

In Canada, stillbirths include all fetal deaths with a birth weight of at least $500 \mathrm{~g}$ or a gestational age at delivery of at least 20 weeks (irrespective of the timing of the fetal death or whether the death followed a pregnancy termination). ${ }^{1}$ We included all live births and stillbirths registered to residents of British Columbia (including home births attended by a registered midwife) and obtained data from the British Columbia Perinatal Data Registry. This comprehensive, population-based database contains detailed information on childbirth-related outcomes and obstetric care services in the province. Data quality has been continually assessed by logic and consistency checks, and the database has been used extensively for health planning and research purposes.

Data for our study were compiled by trained medical-record abstractors using standardized forms. We included data for the fiscal years from Apr. 1, 2000, to Mar. 31, 2011 (hereafter referred to as years 2000 to 2010).

\section{Outcome measures}

The primary outcomes were rates of stillbirth per 1000 total births (live births and stillbirths) by gestational age and birth weight. Gestational age at delivery was determined using a hierarchical algorithm based on the date of last menstrual period, earliest ultrasound before 20 weeks' gestation, pediatric examination of the newborn and other documentation in the medical charts. Temporal changes in stillbirth rates were assessed using birth weight-proportionate mortality (stillbirths in a birth weight category divided by total births in all birth weight categories) and gestational age-proportionate mortality (stillbirths in a gestational age category divided by total births in all gestational age categories). Gestational agespecific stillbirth rates were calculated using the fetuses-at-risk approach (stillbirths in any gestational week divided by fetuses at risk for stillbirth in that week). ${ }^{14,15}$

Other outcomes of interest included rates of spontaneous stillbirth and rates of congenital anomalies among live-born infants. Temporal trends in rates of spontaneous stillbirth were examined after we excluded pregnancy terminations that resulted in a stillbirth (hereafter referred to as "pregnancy terminations" unless specified otherwise). (Pregnancy terminations that result in a stillbirth or a live birth are recorded using a specific variable field in the British Columbia Perinatal Data Registry.) We identified congenital anomalies using the International Classification of Diseases (codes 740-759 in the 9th revision, and Q codes in the enhanced Canadian edition of the 10th revision [ICD-10-CA]). We estimated the prevalence of congenital anomalies among live births in each study period. We used ICD-10-CA code O31.12 to identify fetal reduction carried out in multifetal pregnancies (available for 2009-2010 only).

\section{Statistical analysis}

Stillbirth rates were examined by year to ascertain the full temporal pattern; they were also examined in 3-year increments to ensure stable estimates within small strata. We analyzed temporal trends by contrasting rates in earlier versus later years, with the magnitude of the change expressed using rate ratios and $95 \%$ confidence intervals (CIs). We assessed the statistical significance of annual trends in stillbirth rates using a $\chi^{2}$ test for a linear trend in proportions. Logistic regression was used to examine temporal trends in rates of spontaneous stillbirth after adjustment for maternal age, parity, weight before pregnancy and multiple births.

\section{Ethics approval}

Approval of the study design was obtained from the Ethics Review Board of the Children's and Women's Hospital of British Columbia.

\section{Results}

A total of 461083 live births and 3991 stillbirths were registered in British Columbia between 2000 and 2010. Overall, 3.6\% of the women were less than 20 years of age, and $21.6 \%$ were 35 years and older; $46.1 \%$ were nulliparous; $41.2 \%$ weighed less than $60 \mathrm{~kg}$ before pregnancy, and $7.5 \%$ weighed $90 \mathrm{~kg}$ or more before pregnancy; and $3.0 \%$ had a multiple birth.

\section{All stillbirths}

The overall stillbirth rate increased by $31 \%(95 \%$ CI $13 \%$ to $50 \%$ ), from 8.08 per 1000 total births in 2000 to 10.55 per 1000 in 2010 . Among singleton births, the stillbirth rate increased by $34 \%$ (95\% CI $16 \%$ to $56 \%$ ), from 7.62 per 1000 total births in 2000 to 10.24 per 1000 in 2010 . Among multiple births, the rate decreased by $19 \%(95 \%$ CI $-52 \%$ to $36 \%$ ), from 24.95 per 1000 total births in 2000 to 20.17 per 1000 in 2010 .

When we examined all stillbirths by birthweight category, we observed a significant increase in the rate of stillbirths in the birthweight category of less than $500 \mathrm{~g}$, from 2.36 per 1000 total births in 2000 to 2.84 per 1000 in $2010\left(p_{\text {trend }}=0.03\right)$. The rate in the category of 500-999 g showed a nonlinear pattern (Table 1). In the category of $1000 \mathrm{~g}$ or more, the stillbirth rate decreased significantly, from 2.73 per 1000 total births in 2000 to 1.95 per 1000 in 2010 
$\left(p_{\text {trend }}=0.009\right)$. In the group with missing data on birth weight, the stillbirth rate increased significantly, from 1.67 per 1000 total births in 2000 to 4.54 per 1000 in 2010 ( $\left.p_{\text {trend }}<0.001\right)$.

Table 2 presents the frequency of stillbirths by gestational age. Stillbirths occurring before 22 weeks increased significantly during the study period, from 2.71 per 1000 total births in 2000 to 3.61 per 1000 in $2010\left(p_{\text {trend }}<0.001\right)$.
The same was true for stillbirths occurring from 22 to 27 weeks, increasing from 2.19 per 1000 total births in 2000 to 3.79 per 1000 in 2010 $\left(p_{\text {trend }}<0.001\right)$. Stillbirths occurring at 28 weeks or later and those with missing data on gestational age did not show a significant linear trend.

When we examined all stillbirths according to whether they were spontaneous or resulted from a termination, we found different temporal trends.

Table 1: Incidence of stillbirths in British Columbia from 2000 to 2010, by birth weight

\begin{tabular}{|c|c|c|c|c|c|c|}
\hline \multirow[b]{2}{*}{ Year } & \multicolumn{5}{|c|}{ Birth weight, g; no. of stillbirths (rate per 1000 total births*) } & \multirow[b]{2}{*}{ Total births } \\
\hline & $<500$ & 500-999 & $\geq 1000$ & Missing & Total & \\
\hline 2000 & $96(2.36)$ & $53(1.31)$ & $111(2.73)$ & $68(1.67)$ & 328 (8.08) & 40599 \\
\hline 2001 & $74(1.83)$ & $39(0.96)$ & $112(2.77)$ & $63(1.56)$ & $288(7.12)$ & 40450 \\
\hline 2002 & $135(3.33)$ & $53(1.31)$ & $93(2.29)$ & $39(0.96)$ & $320(7.90)$ & 40525 \\
\hline 2003 & $97(2.39)$ & $54(1.33)$ & $93(2.29)$ & $54(1.33)$ & $298 \quad(7.35)$ & 40543 \\
\hline 2004 & $91(2.23)$ & $59(1.45)$ & 77 (1.89) & $64(1.57)$ & $291 \quad(7.14)$ & 40743 \\
\hline 2005 & $129(3.13)$ & $57(1.38)$ & $91(2.21)$ & 55 (1.34) & 332 (8.06) & 41169 \\
\hline 2006 & $130(3.07)$ & $63(1.49)$ & $108(2.55)$ & $78(1.84)$ & 379 (8.95) & 42368 \\
\hline 2007 & $116(2.61)$ & $76(1.71)$ & $109(2.46)$ & 66 (1.49) & $367 \quad(8.27)$ & 44372 \\
\hline 2008 & $132(2.94)$ & 75 (1.67) & $104(2.31)$ & $124(2.76)$ & $435 \quad(9.68)$ & 44926 \\
\hline 2009 & $121(2.67)$ & $68(1.50)$ & 85 (1.88) & $214(4.72)$ & $488(10.77)$ & 45304 \\
\hline 2010 & $125(2.84)$ & $54(1.23)$ & $86(1.95)$ & $200(4.54)$ & $465(10.55)$ & 44075 \\
\hline Total & $1246(2.68)$ & $651(1.40)$ & $1069(2.30)$ & $1025(2.20)$ & 3991 (8.58) & 465074 \\
\hline$p_{\text {trend }} \uparrow$ & 0.03 & 0.06 & 0.009 & $<0.001$ & $<0.001$ & - \\
\hline
\end{tabular}

Table 2: Incidence of stillbirths in British Columbia from 2000 to 2010, by gestational age

\begin{tabular}{|c|c|c|c|c|c|c|}
\hline \multirow[b]{2}{*}{ Year } & \multicolumn{5}{|c|}{ Gestational age, wk; no. of stillbirths (rate per 1000 total births*) } & \multirow[b]{2}{*}{ Total births } \\
\hline & $<22$ & $22-27$ & $\geq 28$ & Missing & Total & \\
\hline 2000 & $110(2.71)$ & $89(2.19)$ & $110(2.71)$ & $19(0.47)$ & 328 (8.08) & 40599 \\
\hline 2001 & $80(1.98)$ & $74(1.83)$ & $117(2.89)$ & $17(0.42)$ & $288(7.12)$ & 40450 \\
\hline 2002 & $89(2.20)$ & $111(2.74)$ & $97(2.39)$ & $23(0.57)$ & $320(7.90)$ & 40525 \\
\hline 2003 & $91(2.24)$ & $90(2.22)$ & $101(2.49)$ & $16(0.39)$ & $298 \quad(7.35)$ & 40543 \\
\hline 2004 & $89(2.18)$ & $86(2.11)$ & $88(2.16)$ & $28(0.69)$ & 291 (7.14) & 40743 \\
\hline 2005 & $104(2.53)$ & $96(2.33)$ & $104(2.53)$ & $28(0.68)$ & 332 (8.06) & 41169 \\
\hline 2006 & $116(2.74)$ & $129(3.04)$ & $117(2.76)$ & $17(0.40)$ & 379 (8.95) & 42368 \\
\hline 2007 & $99(2.23)$ & $136(3.06)$ & $114(2.57)$ & $18(0.41)$ & 367 (8.27) & 44372 \\
\hline 2008 & 169 (3.76) & $126(2.80)$ & $112(2.49)$ & $28(0.62)$ & $435 \quad(9.68)$ & 44926 \\
\hline 2009 & $171(3.77)$ & 167 (3.69) & $111(2.45)$ & $39(0.86)$ & $488(10.77)$ & 45304 \\
\hline 2010 & $159(3.61)$ & 167 (3.79) & $115(2.61)$ & $24(0.54)$ & $465(10.55)$ & 44075 \\
\hline Total & 1277 (2.75) & $1271(2.73)$ & $1186(2.55)$ & $257(0.55)$ & 3991 (8.58) & 465074 \\
\hline$p_{\text {trend }} \uparrow$ & $<0.001$ & $<0.001$ & 0.65 & 0.08 & $<0.001$ & - \\
\hline
\end{tabular}


Figure 1 shows the temporal trends in the rates of spontaneous stillbirths and of all stillbirths. The rate of all stillbirths increased significantly $\left(p_{\text {trend }}<0.001\right)$, whereas the rate of spontaneous stillbirths decreased nonsignificantly by $16 \%$, from 5.7 per 1000 total births in 2000 to 4.8 per 1000 in 2010 ( $\left.p_{\text {trend }}=0.4\right)$.

Figure 2 shows changes in the rates of stillbirth by gestational age during the first 3 years of the study (2000-02) and the last 3 years (200810). The overall rate of stillbirths was high at early gestation (20-23 wk) in 2000-02; it was even higher in 2008-10, with a less pronounced rise at late gestation and no stillbirths at 42 weeks or later (Figure 2A). When we analyzed only pregnancy terminations that resulted in stillbirth, we observed large changes in the rates at early gestation in 2008-10 (Figure 2B). After exclusion of pregnancy terminations, we noted marginal changes in the rates of spontaneous stillbirth by gestational age (Figure 2C).

Table 3 shows unadjusted and adjusted temporal trends in the rates of spontaneous stillbirths with a birth weight of $1000 \mathrm{~g}$ or more (excluding births with missing data on birth weight). In the unadjusted model, the rates declined significantly between 2000 and 2010 (odds ratio [OR] 0.70, $95 \%$ CI 0.53 to 0.94$)$. With year entered as a continuous variable, spontaneous stillbirths declined by $3 \%$ per year (OR $0.97,95 \%$ CI 0.95 to 0.99 ). Adjustment for maternal age, parity, weight before pregnancy and multiple births had a small, nonsignificant effect on the temporal change in rates of spontaneous stillbirths (adjusted OR 0.67, $95 \%$ CI 0.50 to 0.90 ). In the model with year entered as a continuous variable, adjustment en- hanced the effect on rates marginally to a $4 \%$ decline per year (adjusted OR $0.96,95 \%$ CI 0.95 to 0.98 ).

Temporal trends in the rate of spontaneous stillbirths at 28 weeks' gestation or later showed nonsignificant declines between 2000 and 2010 (OR $0.93,95 \%$ CI 0.71 to 1.20 ). Adjustment for potential confounders had a nonsignificant effect on the temporal decrease in stillbirth rates between 2000 and 2010 (adjusted OR 0.89, 95\% CI 0.68 to 1.16 ).

The overall rate of pregnancy terminations, whether resulting in a stillbirth or a live birth, increased from 2.4 per 1000 total births in 200002 to 5.7 per 1000 in $2008-10$ (133\% increase, $95 \%$ CI $104 \%$ to $166 \%$ ). The prevalence of congenital anomalies among live-born infants decreased from 5.21 per 100 live births in 2000-02 to 4.77 per 100 in $2008-10$ (9\% decrease, $95 \%$ CI $5 \%$ to $12 \%$ ). The rate of fetal reduction for multifetal gestation (resulting in at least one stillbirth or live birth) in 2009-10 was 0.42 per 1000 pregnancies.

\section{Interpretation}

The overall rate of stillbirths in British Columbia increased by $31 \%$ from 2000 to 2010 . This temporal trend was due to increases in pregnancy terminations. The rate of spontaneous stillbirths with a birth weight of $1000 \mathrm{~g}$ or more declined significantly, whereas rates of spontaneous stillbirth at 28 weeks' gestation or later showed a nonsignificant decline. The observed increase in stillbirths due to pregnancy termination was accompanied by a simultaneous decrease in the

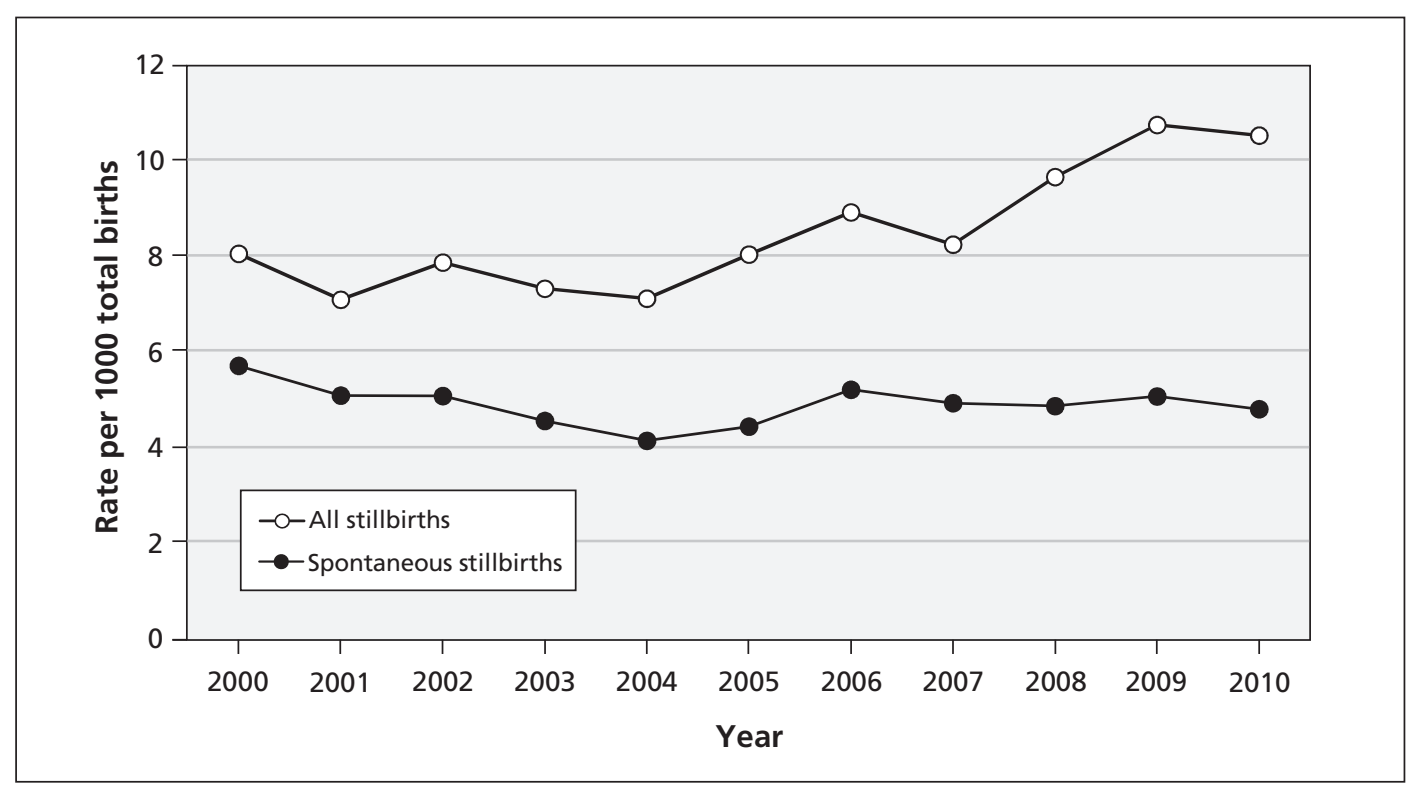

Figure 1: Rates of all stillbirths and of spontaneous stillbirths (excluding pregnancy terminations) in British Columbia, from 2000 to 2010 . Total births (live births and stillbirths) served as the denominator. 
prevalence of congenital anomalies among liveborn infants. This concurrence suggests that advances in, and increased uptake of, prenatal diagnosis are having a population-level impact on the timing of death and the gestational age at delivery of fetuses with congenital anomalies.

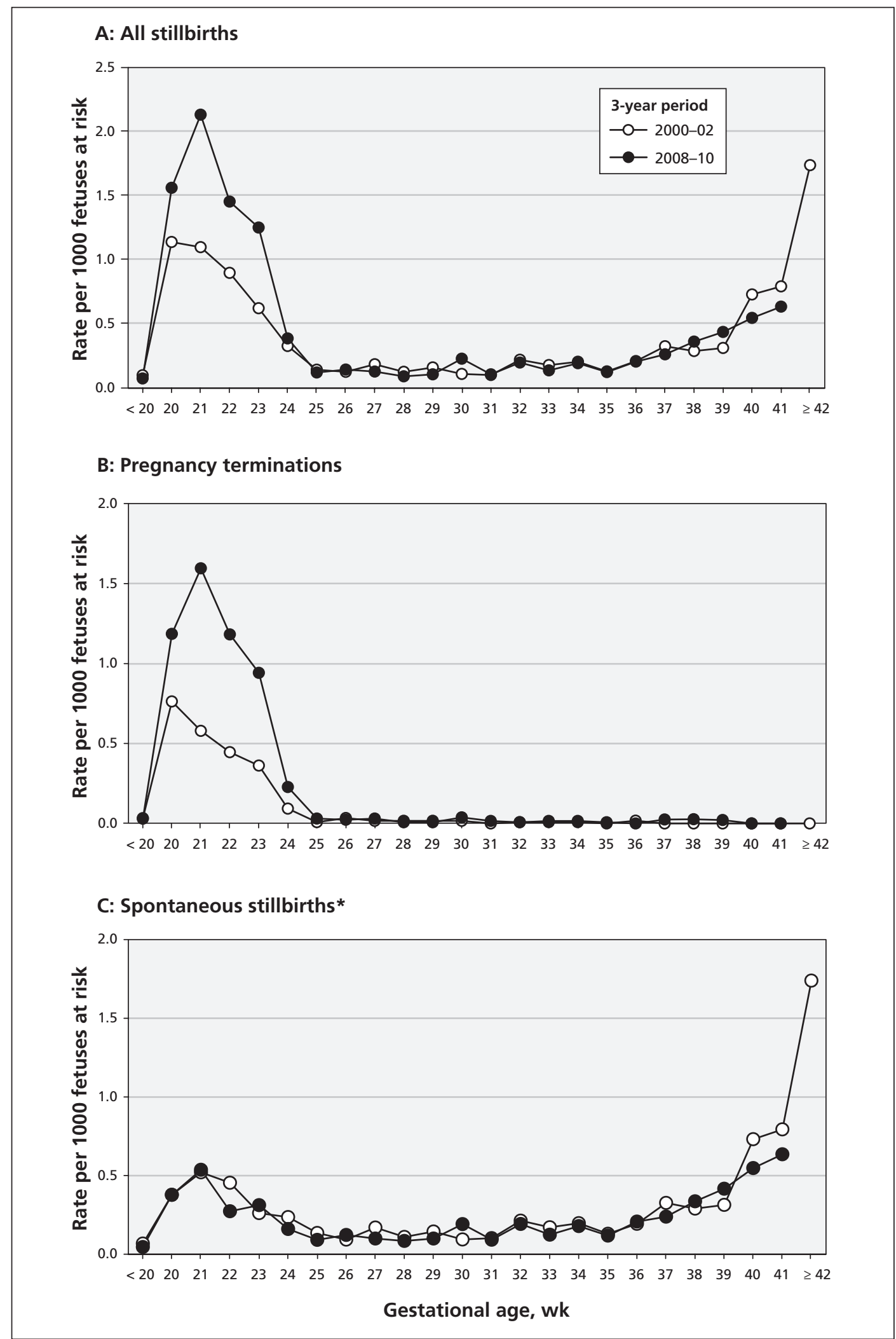

Figure 2: Stillbirth rates by gestational age in the first 3 years of the study period (2000-02) and the last 3 years (2008-10). *Excludes pregnancy terminations. 
Stillbirths following termination of pregnancy constituted $26 \%$ of fetal deaths in New Zealand in

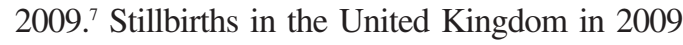
included a smaller proportion of pregnancy terminations because pregnancy terminations were excluded from stillbirth calculations in England and Wales (but not Scotland). ${ }^{8}$ Not surprisingly, the proportion of stillbirths with a major anomaly

Table 3: Unadjusted and adjusted temporal trends in spontaneous stillbirths* among births with a weight of at least $1000 \mathrm{~g}$

\begin{tabular}{|c|c|c|c|c|}
\hline Factor & $\begin{array}{l}\text { Unadjusted OR }+ \\
(95 \% \mathrm{Cl})\end{array}$ & $p$ value $\neq$ & $\begin{array}{l}\text { Adjusted OR } \dagger \\
(95 \% \mathrm{Cl})\end{array}$ & $p$ value $\ddagger$ \\
\hline \multicolumn{5}{|l|}{ Year } \\
\hline 2000 & 1.00 (ref) & - & 1.00 (ref) & - \\
\hline 2001 & $0.99(0.76-1.30)$ & 0.96 & $0.98(0.75-1.28)$ & 0.9 \\
\hline 2002 & $0.79(0.60-1.05)$ & 0.1 & $0.78(0.58-1.03)$ & 0.08 \\
\hline 2003 & $0.84(0.63-1.10)$ & 0.2 & $0.77(0.58-1.02)$ & 0.07 \\
\hline 2004 & $0.69(0.51-0.92)$ & 0.01 & $0.66(0.49-0.89)$ & 0.006 \\
\hline 2005 & $0.77(0.58-1.02)$ & 0.07 & $0.73(0.55-0.97)$ & 0.03 \\
\hline 2006 & $0.91(0.69-1.19)$ & 0.5 & $0.85(0.64-1.11)$ & 0.2 \\
\hline 2007 & $0.85(0.65-1.11)$ & 0.2 & $0.79(0.60-1.04)$ & 0.09 \\
\hline 2008 & $0.83(0.63-1.09)$ & 0.2 & $0.74(0.56-0.98)$ & 0.03 \\
\hline 2009 & $0.63(0.47-0.84)$ & 0.002 & $0.58(0.43-0.78)$ & $<0.001$ \\
\hline 2010 & $0.70(0.53-0.94)$ & 0.02 & $0.67(0.50-0.90)$ & 0.007 \\
\hline \multicolumn{5}{|l|}{ Age, yr } \\
\hline$<20$ & $1.28(0.92-1.79)$ & 0.1 & $1.17(0.84-1.63)$ & 0.4 \\
\hline $20-24$ & 1.00 (ref) & - & 1.00 (ref) & - \\
\hline $25-29$ & $0.96(0.78-1.17)$ & 0.7 & $1.01(0.82-1.23)$ & 0.9 \\
\hline $30-34$ & $0.94(0.77-1.14)$ & 0.5 & $1.02(0.83-1.24)$ & 0.9 \\
\hline $35-39$ & $0.99(0.80-1.23)$ & 0.9 & $1.08(0.86-1.35)$ & 0.5 \\
\hline$\geq 40$ & $1.69(1.26-2.27)$ & $<0.001$ & $1.76(1.30-2.37)$ & $<0.001$ \\
\hline \multicolumn{5}{|l|}{ Parity } \\
\hline 0 & $1.33(1.16-1.51)$ & $<0.001$ & $1.42(1.24-1.62)$ & $<0.001$ \\
\hline $1-2$ & 1.00 (ref) & - & 1.00 (ref) & - \\
\hline $3-4$ & $1.82(1.41-2.34)$ & $<0.001$ & $1.65(1.28-2.13)$ & $<0.001$ \\
\hline$\geq 5$ & $2.44(1.48-4.03)$ & $<0.001$ & $1.96(1.18-3.25)$ & 0.009 \\
\hline \multicolumn{5}{|c|}{$\begin{array}{l}\text { Weight before } \\
\text { pregnancy, kg }\end{array}$} \\
\hline$<60$ & $1.11(0.92-1.36)$ & 0.3 & $1.10(0.91-1.34)$ & 0.3 \\
\hline $60-69$ & 1.00 (ref) & - & 1.00 (ref) & - \\
\hline $70-79$ & $1.44(1.14-1.82)$ & 0.003 & $1.45(1.15-1.83)$ & 0.002 \\
\hline $80-89$ & $1.11(0.79-1.55)$ & 0.5 & $1.13(0.81-1.58)$ & 0.5 \\
\hline$\geq 90$ & $1.78(1.35-2.36)$ & $<0.001$ & $1.84(1.39-2.43)$ & $<0.001$ \\
\hline Missing & $2.12(1.76-2.56)$ & $<0.001$ & $2.16(1.79-2.61)$ & $<0.001$ \\
\hline $\begin{array}{l}\text { Multiple } \\
\text { birth }\end{array}$ & $1.48(1.09-2.01)$ & 0.01 & $1.40(1.02-1.91)$ & 0.04 \\
\hline
\end{tabular}

Note: $\mathrm{Cl}=$ confidence interval, $\mathrm{OR}=$ odds ratio, ref = reference group.

*Excludes pregnancy terminations that resulted in stillbirth.

tThe unadjusted ORs show the effect of each factor independent of the other factors; the adjusted ORs show the effect after adjustment for all other factors in the table. $\ddagger$ Wald $\chi^{2}$ test. as the primary cause of death varied between these regions: $8.0 \%$ in England, $5.7 \%$ in Wales and $15.6 \%$ in Scotland. ${ }^{8}$ Differences in the definition of stillbirth affect the frequency with which pregnancy terminations are included among stillbirths. Most pregnancy terminations in our study occurred between 20 and 23 weeks' gestation, whereas some countries (e.g., the UK) consider fetal deaths to be stillbirths only if they occur at 24 weeks' gestation or later. Such variations in definitions and birth registration practices are responsible for changes in the ranking of countries based on crude stillbirth rates versus ranking based on rates of stillbirths with a birth weight of 1000 g or more. ${ }^{16-19}$

Concerns regarding maternal and fetal health status are not misplaced given recent increases in the frequency of risk factors for adverse perinatal outcomes, including higher maternal age, weight before pregnancy and multiple births. ${ }^{11-13}$ However, we found that adjustment for such changes did not substantially accentuate the declining trends in spontaneous stillbirth in our study (Table 3). Recent developments that have enhanced maternal and fetal health include reductions in maternal smoking, ${ }^{1,20}$ fortification of food with folic acid, ${ }^{21,22}$ therapies for pre-eclampsia ${ }^{23}$ and improvements in fetal growth. ${ }^{1,20}$

Prenatal diagnosis has also shifted the burden of illness associated with congenital anomalies. Infant deaths and late fetal deaths due to serious congenital anomalies are increasingly being replaced by pregnancy terminations before 24 weeks' gestation following prenatal diagnosis. ${ }^{24,25}$ Although our study showed that the increase in stillbirths due to pregnancy termination (presumably after prenatal diagnosis) occurred simultaneously with a reduction in the prevalence of congenital anomalies among liveborn infants, other factors may have also contributed to the latter change. For instance, fortification of food with folic acid, introduced in Canada in 1998, may have contributed to declines in the prevalence of congenital anomalies. ${ }^{21,22}$ In addition, increases in maternal age may have contributed to increases in the prevalence of Down syndrome among live-born infants. ${ }^{1}$

Surveillance for preventable stillbirth remains an important public health function and requires that a distinction be made between stillbirths that occur spontaneously and those that follow pregnancy termination for serious congenital anomalies or other reasons. The processes associated with stillbirth registration following pregnancy termination can also cause unintended psychosocial harm to women and their families. For instance, in many jurisdictions, parental involvement is required in the stillbirth registration process (similar to live birth registration), which 
often places an undue psychological burden on parents. The situation can be exacerbated when the stillbirth registration occurs some time after the fetal death, as in case of fetal reduction for multifetal pregnancy (e.g., reduction of a triplet pregnancy to a twin pregnancy at 10-14 weeks' gestation, delivery of twins and the dead fetus at term, and the need for stillbirth registration because the dead fetus was delivered after 20 weeks' gestation). One solution to this procedural problem would have the onus for stillbirth registration (and disposal of the fetal remains) placed on the health care provider and health care system and not on the distressed parents.

\section{Strengths and limitations}

Our study was based on a population registry of live births and stillbirths and included both hospital and home births. The registry is comprehensive, and the primary findings of our study are unlikely to have been compromised by missing live births or stillbirths. Nevertheless, some secondary analyses in our study were affected by missing data, especially missing information on birth weight. However, the temporal increase in the rate of stillbirths with missing birth-weight data probably occurred because pregnancy termination procedures can interfere with the accurate estimation of birth weight (but not gestational age, as shown in Table 2). Other limitations of our study include potential inaccuracies and missing information on self-reported maternal weight before pregnancy.

\section{Conclusion}

Increases in pregnancy terminations were responsible for the increases observed in stillbirth rates from 2000 to 2010 and were associated with declines in the prevalence of congenital anomalies among live-born infants. Future research examining temporal trends and regional variations in stillbirth rates should focus separately on spontaneous stillbirths and those due to pregnancy termination.

\section{References}

1. Public Health Agency of Canada. Canadian perinatal health report - 2008 edition. Ottawa (ON): The Agency; 2008.

2. Births 2009. Ottawa (ON): Statistics Canada, Health Statistics Division; 2012. Cat. no. 84F0210X.

3. Australia's mothers and babies 2000. Perinatal statistics series no. 12. Canberra (Australia): Australian Institute of Health and Welfare, National Perinatal Statistics Unit; 2003. Cat. no. PER 21.

4. Li Z, McNally L, Hilder L, et al. Australia's mothers and babies 2009. Perinatal statistics series no. 25. Sydney (Australia): Australian Institute of Health and Welfare, National Perinatal Epidemiology and Statistics Unit; 2011. Cat. no. PER 52.

5. Perinatal and maternal mortality in New Zealand 2007: third report to the Minister of Health July 2008 to June 2009. Wellington (NZ): Ministry of Health; 2009.

6. Perinatal and maternal mortality in New Zealand 2008: fourth report to the Minister of Health July 2009 to June 2010. Wellington (NZ): Ministry of Health; 2010.

7. Fifth annual report of the Perinatal and Maternal Mortality
Review Committee: reporting mortality 2009. Wellington (NZ): Health Quality and Safety Commission; 2011.

8. Centre for Maternal and Child Enquiries. Perinatal mortality 2009: United Kingdom. London (UK): The Centre; 2011.

9. MacDorman M, Kirmeyer S. The challenge of fetal mortality. NCHS data brief no. 16. Hyattsville (MD): National Center for Health Statistics; 2009

10. Joseph KS. Theory of obstetrics: an epidemiologic framework for justifying medically indicated early delivery. BMC Pregnancy Childbirth 2007; 7:4.

11. Cnattingius S, Lambe M. Trends in smoking and overweight during pregnancy: prevalence, risks of pregnancy complications, and adverse pregnancy outcomes. Semin Perinatol 2002;26:286-95.

12. Fell DB, Joseph KS, Dodds L, et al. Changes in maternal characteristics in Nova Scotia, Canada from 1988 to 2001. Can J Public Health 2005;96:234-8.

13. Glinianaia SV, Rankin J, Bell R, et al. Temporal changes in the distribution of population risk factors attenuate the reduction in perinatal mortality. J Clin Epidemiol 2005;58:1299-307.

14. Yudkin PL, Wood L, Redman CWG. Risk of unexplained stillbirth at different gestational ages. Lancet 1987;1:1192-4.

15. Kramer MS, Liu S, Luo Z, et al. Analysis of perinatal mortality and its components: Time for a change? Am J Epidemiol 2002; 156:493-7.

16. Joseph KS, Liu S, Rouleau J, et al.; Fetal and Infant Health Study Group of the Canadian Perinatal Surveillance System. Influence of definition based versus pragmatic birth registration on international comparisons of perinatal and infant mortality. BMJ 2012;344:e746.

17. Kowaleski J. State definitions and reporting requirements for live births, fetal deaths, and induced terminations of pregnancy (1997 revision). Hyattsville (MD): National Center for Health Statistics; 1997. Available: www.cdc.gov/nchs/data/misc/itop97.pdf (accessed 2013 Mar. 25).

18. Lack N, Zeitlin J, Krebs L, et al. Methodological difficulties in the comparison of indicators of perinatal health across Europe. Eur J Obstet Gynecol Reprod Biol 2003;111:S33-44.

19. Macfarlane A, Gissler M, Bolumar F, et al. The availability of perinatal health indicators in Europe. Eur J Obstet Gynecol Reprod Biol 2003;111:S15-32.

20. Kramer MS, Morin I, Yang H, et al. Why are babies getting bigger? Temporal trends in fetal growth and its determinants. J Pediatr 2002;141:538-42.

21. De Wals P, Tairou F, Van Allen MI, et al. Reduction in neuraltube defects after folic acid fortification in Canada. $N$ Engl $J$ Med 2007;357:135-42.

22. Honein MA, Paulozzi LJ, Mathews TJ, et al. Impact of folic acid fortification of the US food supply on the occurrence of neural tube defects. JAMA 2001;285:2981-6.

23. Altman D, Carroli G, Duley L, et al.; Magpie Trial Collaboration Group. Do women with pre-eclampsia, and their babies, benefit from magnesium sulphate? The Magpie Trial: a randomised placebo-controlled trial. Lancet 2002;359:1877-90.

24. Liu S, Joseph KS, Wen SW. Trends in fetal and infant deaths due to congenital anomalies. Semin Perinatol 2002;26:268-76.

25. Liu S, Joseph KS, Kramer MS, et al. Relationship of prenatal diagnosis and pregnancy termination to overall infant mortality in Canada. JAMA 2002;287:1561-7.

Affiliations: From Perinatal Services BC (Joseph, Kinniburgh, Hutcheon, Lee); the Department of Obstetrics and Gynaecology, and the School of Population and Public Health (Joseph, Hutcheon, Mehrabadi), University of British Columbia; and the Women's Hospital and Health Centre of British Columbia (Joseph, Hutcheon, Basso, Davies), Vancouver, BC

Contributors: K.S. Joseph and Lily Lee proposed the study from a surveillance standpoint, and Melanie Basso and Cheryl Davies raised concerns related to stillbirth registration and its impact on women and families. K.S. Joseph conducted the data analysis with the help of Brooke Kinniburgh and drafted the manuscript. All of the authors reviewed the preliminary and final analyses, provided critical comments on the initial drafts of the manuscript and approved the final version of the manuscript submitted for publication.

Acknowledgements: K.S. Joseph is supported by the Child and Family Research Institute. Jennifer Hutcheon is the recipient of a Scholar Award from the Michael Smith Foundation for Health Research and a New Investigator Award from the Canadian Institutes of Health Research (CIHR). Azar Mehrabadi is supported by a CIHR Team grant in Severe Maternal Morbidity (grant no. MAH-115445). 